\title{
ATIVOS INTANGÍVEIS
}

Os ativos intangíveis exercem um papel cada vez mais importante na sustentação das vantagens competitivas e na criação de valor econômico das empresas. Há de se destacar a multiplicidade de enfoques no estudo desse tema. As diferentes perspectivas são fundamentais para o entendimento da relação entre os ativos intangíveis e a criação de valor. As indicações incluem perspectivas provenientes da economia (abordagens evolucionárias e teorias de organização industrial), da área de estratégia (resource-based view e dynamic capabilities), das áreas de finanças e da contabilidade (agency theory e assimetria informacional). Eduardo Kazuo Kayo, professor da Universidade Presbiteriana Mackenzie, recomenda as seguintes obras:

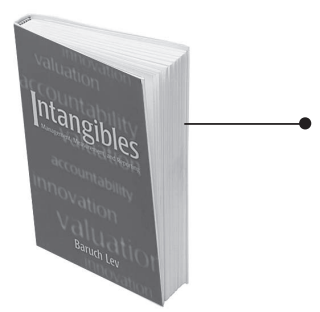

INTANGIBLES: Management, Measurement, and Reporting. Baruch Lev. Washington: Brookings, 2001. 216 p. Este livro, escrito por um dos pesquisadores mais renomados na área contábil, é uma das referências mais importantes no que diz respeito a ativos intangíveis. O professor Baruch Lev apresenta, com profundidade e de forma bastante clara, questões fundamentais para se entender o porquê da crescente importância dos intangíveis. Fundamentos econômicos (efeitos de escala e escopo, externalidades de rede), contábeis (registro e divulgação de informações sobre intangíveis) e financeiros (risco e retorno) são tratados com muita propriedade.

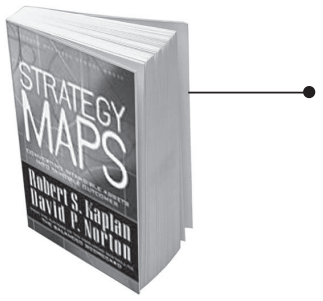

STRATEGY MAPS: Converting Intangible Assets into Tangible Outcomes. Robert S. Kaplan e David P. Norton. Boston: Harvard, 2004. 454 p.

Esta obra foi escrita pelos criadores do Balanced Scorecard, que se tornou um instrumento de grande sucesso acadêmico e comercial. Neste novo livro, Kaplan e Norton retomam a discussão sobre as quatro perspectivas originais do Balanced Scorecard (financeira, clientes, processos internos e aprendizado/crescimento), apresentando porém suas relações com a criação de valor a longo prazo. Os autores chamam a atenção para a importância de ver as quatro perspectivas de forma holística e integrada.

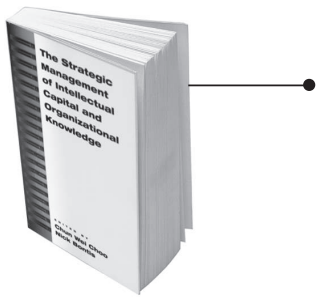

THE STRATEGIC MANAGEMENT OF INTELLECTUAL CAPITAL AND ORGANIZATIONAL KNOWLEDGE. Chun Wei Choo e Nick Bontis (Orgs.). New York: Oxford, 2002. 748 p.

Esta obra é uma coletânea de textos que propõe abordar uma corrente teórica chamada knowledgebased view. Essa corrente de certa forma aborda vários aspectos teóricos que envolvem a resourcebased view. Nas palavras dos próprios organizadores, a obra traz à discussão três questões principais: Como as organizações criam conhecimento e capital intelectual? Como as organizações gerenciam o fluxo e a acumulação de conhecimentos e capital intelectual de forma a sustentar suas vantagens competitivas? Quais princípios e ações constituem uma estratégia baseada no conhecimento?

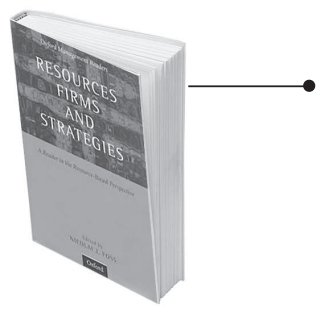

RESOURCES, FIRMS, AND STRATEGIES: a Reader in the Resource-Based Perspective. Nicolai J. FoSS (Org.). New York: Oxford, 1997. 378 p.

A obra reúne textos de importantes pesquisadores da linha de resource-based view, como Margaret Peteraf, David Teece, Birger Wernerfelt, Richard Rumelt e Jay Barney. Além dessa visão contemporânea, textos de autores clássicos como Edith Penrose, Alfred Chandler e Harold Demsetz também estão incluídos neste livro. Trata-se de uma obra que sintetiza a fundamentação básica da resource-based view, linha de pesquisa que se constitui numa das mais importantes da área de estratégia.

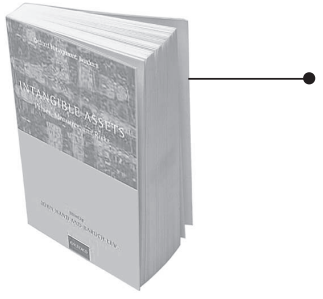

INTANGIBLE ASSETS: Values, Measures, and Risks. John R. M. Hand e Baruch Lev. New York: Oxford, 2003. 537 p.

Esta coletânea de textos traz importantes discussões sobre questões econômicas, financeiras e contábeis a respeito dos ativos intangíveis. A primeira parte do livro contextualiza os ativos intangíveis na chamada nova economia. A segunda apresenta pesquisas empíricas que analisam a relação entre diversos tipos de ativos intangíveis e a criação de valor. A terceira parte discute os atuais problemas de divulgação e assimetria informacional relativos aos intangíveis. A quarta parte, por fim, é de natureza prescritiva e traz sugestões para resolver ou minimizar os problemas discutidos na parte três. 